\title{
ANÁLISE DE PLANOS DE COMUNICAÇÃO EM BIBLIOTECAS COMO SUBSÍDIOS À CONSTRUÇÃO DO PLANO DE COMUNICAÇÃO INTEGRADA DA BIBLIOTECA DA CASA DA JUVENTUDE PE. BURNIER, EM GOIÂNIA, GOIÁS
}

\author{
LANA KEREN DE MENDONÇA* \\ RUBEM BORGES TEIXEIRA RAMOS ${ }^{* *}$
}

\begin{abstract}
RESUMO
Retoma-se a relação entre a informação e a comunicação. Discorrese sobre teorias da comunicação interna e seus possíveis usos em bibliotecas. Em especial, foram levantados aspectos necessários para compor um plano de comunicação interna à Biblioteca Pe. Albano Trinks, da instituição jesuítica Casa da Juventude Pe. Burnier, em Goiânia - GO. Foram analisados quatro planos de comunicação em diferentes bibliotecas, para facilitar uma delineação geral do plano de comunicação interna em uma biblioteca. Reforça a importância dos colaboradores de bibliotecas como os primeiros usuários dos produtos e serviços dessa mesma unidade de informação. Os aspectos de um plano de comunicação interna confirmam a biblioteca como um bem sociocultural da sociedade e os colaboradores, dessa unidade, como pessoas fundamentais à difusão do conhecimento disponível na biblioteca.
\end{abstract}

PALAVRAS-CHAVE: Comunicação interna; biblioteca; plano de comunicação; comunicação em bibliotecas; unidades de informação.

\begin{abstract}
Incorporates the relationship between information and communication. Discourses on theories of internal communication and its possible uses in libraries. In particular were raised aspects necessary to compose a plan of internal communication to the Biblioteca Pe. Albano Trinks of Jesuit institution, Casa da Juventude Pe. Burnier, in Goiânia - GO. We analyzed four communication plans of different libraries to facilitate the delineation of the Plan of internal communication in library. Reinforces the importance of the employees of libraries as the first users of the products and services of this unit of information. The aspects of a plan of internal communication confirm
\end{abstract}

\footnotetext{
*Bibliotecária da Pontifícia Universidade Católica de Goiás.

** Mestre em Ciência da Informação pela Universidade Federal de Minas Gerais UFG. Professor Assistente da Faculdade de Comunicação e Biblioteconomia da Universidade Federal de Goiás - UFG.
} 
the library as a cultural good of society, and the collaborators, this unit, as people fundamental to the dissemination of the knowledge available in the library.

KEYWORDS: Internal communication; library; communication plans; communication in libraries; communication in information units.

\section{INTRODUÇÃO}

Com o objetivo de retomar a relação existente entre informação e comunicação, discorre-se, neste texto, sobre as teorias da comunicação interna e seus possíveis usos e aplicações em bibliotecas. Em especial, serão focados aspectos necessários para compor um plano de comunicação interna à Biblioteca Pe. Albano Trinks da Casa da Juventude Pe. Burnier (CAJU). Esta é uma Biblioteca mista, pois assume de forma concomitante as características e funções de uma biblioteca especializada em juventude, possuindo um acervo sobre juventude, o qual é referência no centro-oeste brasileiro, e também comunitária, porque seu acervo também é composto por vários outros assuntos (literaturas, religião, filosofia, teologia, psicologia, espiritualidade, bíblia, matemática, física, química, história, meio ambiente, entre outros) e não possui ajuda de órgãos públicos para subsidiar sua formação e manutenção.

A Casa da Juventude Pe. Burnier (CAJU) é um Instituto de Formação, Assessoria e Pesquisa Juvenil, localizado em Goiânia/GO. É uma obra apostólica da Companhia de Jesus Jesuítas do Brasil. Juridicamente, trata-se de uma filial da Associação Jesuíta de Educação e Assistência Social (AJEAS). Reconhecida como associação civil sem fins lucrativos, de natureza educacional, cultural, assistencial e de utilidade pública, oferece serviços públicos na perspectiva do projeto de vida e garantia de direitos, tendo como foco os/as adolescentes e jovens empobrecidos, principalmente adolescentes em situação de vulnerabilidade social, e suas famílias.

Compreendem-se quais os limites e as possibilidades de se empregar o conceito e as técnicas de comunicação interna às bibliotecas voltados especificamente para a realidade de Biblioteca da Casa da Juventude. Já que no contexto nacional há ausência de materiais bibliográficos e não bibliográficos direcionados à comunicação em bibliotecas.

Ao delinear um plano de comunicação à biblioteca da CAJU e 
enviá-lo com um pedido de inserção no Plano de Comunicação da instituição, é possível garantir espaços de comunicação à unidade de informação. Entre esses espaços, estão um mural, informativos mensais, site da CAJU, redes sociais (facebook, twitter), falas em reuniões com todos os colaboradores (Reuniões do Conselho Permanente), Webmail (e-mail interno). Após garantidos os espaços/ambientes de comunicação à biblioteca, os serviços e produtos desta serão melhor aproveitados pelos colaboradores da CAJU. Espera-se que essa unidade informacional seja, aos funcionários, um ambiente de capacitação, busca de novos conhecimentos, inovações e ideias diferentes para solução de problemas remanescentes. Pessoas constantemente capacitadas estarão sempre preparadas para mudanças.

Comunicar internamente é um conjunto de ações integradas que visam ouvir, informar, mobilizar, educar, manter coesão interna em torno de valores que necessitam ser compartilhados com todos. Nesse sentido, um dos principais valores que se faz necessário o compartilhamento com os colaboradores é o que a biblioteca é um organismo vivo, objeto de cultura social (todos devem fazer parte dela).

\section{METODOLOGIA}

Quanto à natureza, a pesquisa desenvolvida é a aplicada, pois "objetiva gerar conhecimentos úteis para a aplicação prática e dirigida a solução de problemas específicos. Envolve verdades e interesses locais" (SILVA, 2005, p. 20).

Do ponto de vista de abordagem do problema, a pesquisa é qualitativa. Em uma pesquisa desse tipo, a interpretação dos fenômenos e a atribuição de significados são básicas no processo de pesquisa. O pesquisador analisa seus dados por dedução. (SILVA, 2005).

Classifica-se pelos seus objetivos como pesquisa exploratória. A pesquisa a ser utilizada neste trabalho é a pesquisa exploratória, pois o processo de pesquisa é flexível e não estruturado e tem como objetivo prover critérios para a compreensão. Segundo Silva (2005), a pesquisa exploratória, em geral, assume as formas de pesquisas bibliográficas e estudo de caso.

Os estudos exploratórios podem ter outras funções: aumentar o conhecimento do pesquisador acerca do fenômeno que deseja investigar em estudo posterior; o esclarecimento de conceitos; o estabelecimento de prioridades para futuras pesquisas; a obtenção 
de informação sobre possibilidades práticas de realização de pesquisas em situações de vida real; apresentação de um recenseamento de problemas considerados urgentes. (MIRANDA, 2008, p. 40).

Quanto aos procedimentos técnicos utilizados, esta pesquisa é classificada com pesquisa bibliográfica. Uma pesquisa bibliográfica deverá ser realizada em três etapas: planejamento da pesquisa; elaboração dos elementos textuais; e redação final. No planejamento da pesquisa, foram organizadas as ações, a elaboração do projeto de pesquisa e também a preparação do material para registro das informações. Na fase de elaboração dos elementos textuais, foram elaborados os itens principais do trabalho os quais são: revisão da literatura e conclusão (MARTINS JUNIOR, 2008). É pesquisa bibliográfica, pois foi elaborada a partir de material já publicada como livros, artigos e materiais disponíveis na internet (SILVA, 2005).

A primeira procedência cumprida nesta pesquisa foi a pesquisa bibliográfica. A pesquisa bibliográfica se limitou a publicações de língua portuguesa e espanhola. Os aspectos compreendidos através da pesquisa bibliográfica foram: comunicação organizacional interna; comunicação em unidades de informação; cultura organizacional; comunicação interna em bibliotecas; modelos de plano de comunicação em bibliotecas.

Após a pesquisa bibliográfica, foi realizada uma análise de quatro planos de comunicação em Bibliotecas. Foram analisados três planos de comunicação em bibliotecas da Espanha e um Plano de comunicação integrada de uma biblioteca brasileira.

Para que a pesquisa em questão tivesse maior direcionamento e especificidade, foram delineados aspectos a serem abordados em um plano de comunicação interna à Biblioteca Pe. Albano Trinks da Casa da Juventude Pe. Burnier (CAJU) em Goiânia, Goiás. Esse delineamento resultou das análises de: textos científicos no assunto em questão e da análise dos quatro planos de comunicação em bibliotecas.

\section{UNIDADE DE INFORMAÇÃO - A BIBLIOTECA DA CAJU}

A Biblioteca da CAJU foi inaugurada no dia oito de junho de 1997. Teve sua origem a partir do recebimento, por parte da CAJU, de diversos livros e periódicos da antiga residência dos Jesuítas, localizada em Goiânia. Esse espaço vem consolidando sua imagem 
como referência sobre a temática da adolescência e juventude, na região do Centro-Oeste brasileiro. Em 2012, foi iniciada a automatização em rede do acervo dessa biblioteca pelo Sistema Pergamum (Sistema Integrado de Bibliotecas). Os produtos disponibilizados pela biblioteca aos seus usuários são livros, revistas, jornais, clippings juventude Goiás ${ }^{1}$, anuários, catálogos e outras documentações da Companhia de Jesus, dicionários, enciclopédias, histórias em quadrinhos, CDs, DVDs, audiovisuais e VHS (fitas cassetes).

Os serviços oferecidos por essa unidade informacional são empréstimo domiciliar, acesso livre ao acervo e consulta informatizada; acesso à Internet (Projeto Telecentros.Br - Estação Digital) e à internet pela rede Wi fi (CAJU), atendimento ao usuário local, pelo telefone e/ou e-mail, levantamento bibliográfico, consulta/visita orientada, treinamento de usuários e orientação sobre pesquisa na internet e serviço de alerta de atividades via redes sociais, oficinas de leitura e escrita - "Para gostar de ler", varal literário (com textos e/ou livro infantil) e contação de histórias, orientação sobre usos da internet (e-mail, redes sociais etc.) e uso do pacote BrOffice.org.

O público-alvo da Biblioteca é misto. Internamente, essa unidade atende a adolescentes, jovens e adultos, usuários da CAJU e os seus colaboradores. O público externo da biblioteca são os familiares dos jovens atendidos, pesquisadores da área de juventude e comunidade em geral.

\section{COMUNICAÇÃO, INFORMAÇÃO \& COMUNICAÇÃO INTERNA}

Efetivamente, a palavra comunicação possui seu primeiro significado no vocabulário religioso. Quanto a sua origem epistemológica, a palavra Comunicação vem do latim communicatio, termo formado por três elementos, que são a raiz munis, significando "estar encarregado de", o prefixo $c 0$, o qual expressa "atividade realizada conjuntamente" e a terminação tio, que assegura a ideia de atividade (MARTINO, 2001).

No contexto social do cristianismo antigo, a vida eclesiástica era marcada pelo isolamento e contemplação como condições para se conhecer a Deus. Havia, na época, duas tendências que

1 Recortes de reportagens do Jornal Regional goiano "O popular" sobre juventudes na faixa etária de 13 a 29 anos. São recortadas quaisquer notícias as quais envolvam jovens na faixa etária anteriormente descrita. 
interpretavam este isolamento de maneiras diferentes: os anacoretas e os cenobitas. Os primeiros cultivavam a solidão e viviam de forma inteiramente individual. Os últimos optaram por uma vida em comunidade, os conventos e mosteiros também chamados de Cenóbios, lugar onde se vive em comum. A prática communicatio, ato de tomar a refeição da noite em comum, surge no mosteiro. Essa prática não se resume somente no ato de comer, e sim no ato de comer junto com outros (MARTINO, 2001).

No dicionário, o ato de comunicar significa: "fazer saber"; "participar"; "transmitir mensagem"; "ter passagem comum". A comunicação é o processo que envolve a transmissão e recepção de mensagens entre o emissor e um destinatário ou receptor. Comunicação Interna é o processo de comunicação que ocorre entre a instituição ou organização e o seu público interno (HOUAISS, 2001, p. 781).

Do ponto de vista semiótico, a comunicação situa-se no centro do processo de significação no qual a mensagem (som acústico ou escrita + significado) deixa de ser algo isolado e gera significância a outro ao ser comunicada/transmitida a este. Santo Agostinho, Platão, Aristóteles, Cícero e Quintilhano, dentre outros estudiosos, ocuparam-se com a significação das mensagens e, por consequência, da comunicação. Desde o momento histórico em que a linguagem tornou-se $o$ elo entre indivíduos e o ambiente, a informação passou a ser entendida como o principal elemento que torna possível a significação. "Comunicação e informação são consideradas duas faces de um mesmo fenômeno: a significação" (MACHADO, 2001, p. 295).

A informação é o elemento de transmissão. Uma significação é preservada durante anos, devido à transmissão da informação de significados. Essa informação estará disponível, ao longo de anos, em algum suporte informacional como livros, periódicos, sites e imagens, dentre outros. Essa informação estará acessível aos contemporâneos, pessoas de uma mesma época, por meio da comunicação:

Se a comunicação é essencialmente um transporte no espaço, a transmissão é essencialmente um transporte no tempo. A primeira é pontual ou sincronizante[...] religa, sobretudo contemporâneos [...] A segunda é diacrônica e caminhante... estabelece ligação entre vivos e os mortos, quase sempre, na ausência física dos 'emissores'[...] A comunicação se distingue pelo fato de resumir, enquanto a transmissão se distingue pela prolongação (correndo o risco, com 
esse mesmo objetivo, de condensar suas formas de expressão: divisa, logotipo, apólogo, parábola...) (DEBRAY, 2000, p. 15).

O processo de comunicação pode ser constituído por seis elementos ou "ingredientes": fonte de comunicação; codificador; a mensagem; o canal; o decodificador; o recebedor da comunicação. A fonte de comunicação humana é uma pessoa ou grupo de pessoas com o objetivo de comunicar algo. Os objetivos da fonte são traduzidos num código, numa linguagem. Surge, então, a necessidade de um codificador, responsável por pegar as ideias da fonte e pô-las em um código. O codificador exprimirá os objetivos da fonte em forma de mensagem. O canal é o transmissor da mensagem, o intermediário. $\mathrm{Na}$ outra ponta do canal, há o alvo, recebedor da mensagem. O recebedor necessita colocar a mensagem de uma maneira que lhe seja possível usá-la, ou seja, ele necessita dar sentido à mensagem recebida. $O$ decodificador é um conjunto de habilidades sensoriais do recebedor (BERLO, 1972, p. 35).

A escolha da linguagem e canal ideal (meio) é fundamental para a efetivação do processo de comunicação interna. Essa comunicação interna só será adequada quando os colaboradores conseguirem fazer sentidos (decodificar). As fontes (a organização) necessitam usar um código, linguagem similar aos códigos e linguagem utilizados pelos receptores (os colaboradores). Os colaboradores (receptores) devem ser capazes de entender a mensagem a ponto de conseguirem utilizá-la em seus trabalhos, atividades e atendimento aos públicos internos e externos.

Em uma organização, existem duas redes de comunicação: a formal e a informal. $\mathrm{Na}$ rede formal de comunicação, ocorrem as manifestações oficiais de comunicação, pré-estabelecidas pela instituição e em acordo com a organização hierárquica da mesma. A rede informal comporta as manifestações espontâneas dos colaboradores em sua coletividade, incluindo igualmente as populares redes de boatos e rede sociológica dos grupinhos (TORQUATO, 1986).

Hoje, a comunicação interna pode ser definida como um conjunto de ações que a instituição/organização coordena com o objetivo de "ouvir, informar, mobilizar, educar e manter coesão interna em torno de valores que precisam ser compartilhados por todos". Por seu caráter social, a comunicação interna também é considerada como um dos aspectos motivacionais à organização (CURVELLO, 2012, p. 22).

A comunicação de âmbito social inclui a difusão ideológica e 
simbólica da organização, ou mesmo a cultura organizacional. A ideologia não é formada somente pelo discurso oficial da direção da instituição. Sua elaboração é constituída e acrescida por valores do conjunto de colaboradores/funcionários. Os elementos simbólicos são as expressões que tanto podem construir a identidade organizacional (comunicação e consenso), como ocultar as relações de dominação. Essa cultura define as ações internas da instituição. As contradições, mediações, sucessos, fracassos, facilidades e dificuldades às mudanças institucionais são captadas através da instância Cultura Organizacional (CURVELLO, 2012, p. 22).

Ao recorrer às raízes antropológicas e psicológicas, pode-se captar a cultura de uma organização em três níveis: nível dos artefatos visíveis (documentos, vestuário, padrões de comportamento, arquitetura, layout, ambiente), o nível de valores os quais direcionam o comportamento das pessoas (valores manifestos em relatos e entrevistas) e o nível de valores inconscientes (como os colaboradores pensam, sentem, percebem, a partir de valores conscientemente construídos e que, posteriormente, são absorvidos pelo inconsciente) (SHEIN, 1986 apud CURVELLO, 2012).

Um dos papéis fundamentais da comunicação interna é trabalhar com valores. Destes, um dos principais é o comprometimento. É o trabalho com o comprometimento do pessoal que proporcionará a reunião entre as expectativas pessoais e as da instituição (SEMINÁRIO NACIONAL DE BIBLIOTECAS UNIVERSITÁRIAS, 2012).

\subsection{Comunicação interna em bibliotecas}

A literatura sobre a comunicação interna em bibliotecas no Brasil é bastante escassa e se encontra em construção. Ao tentar superar as limitações da temática na literatura, foram encontradas abordagens de autores brasileiros, portugueses e de uma autora espanhola.

É incontestável a importância da biblioteca como organização social para os contextos educacional, científico e cultural da sociedade. Todas as atividades básicas de biblioteca, como aquisição, processamento, circulação e referência tem por objetivo a comunicação do conhecimento (MULLER; FORTES, 1996). A subutilização dos produtos e serviços desse tipo de unidade de informação já demonstra um grande problema de comunicação em bibliotecas. Outra problemática percebida em várias dessas unidades de informação e na literatura da área é a falta de 
motivação e a não utilização de serviços pelos próprios funcionários dessas organizações.

Lopes (2002, p. 107) pontua consideráveis aspectos motivacionais para o não reconhecimento da importância de bibliotecas por grande parte de brasileiros, como a tradicional separação entre a comunicação e a informação, o que pode impedir ou dificultar a percepção das reais necessidades de comunicação interna e externa dessas organizações. Não há sentido lógico em se tratar de informações registradas (catalogar, classificar, indexar) sem cuidar dos aspectos comunicacionais dessas informações.

Outro aspecto que contribui para a separação entre o tratamento e a comunicação da informação é a falta de profissionalização de grande parte do quadro de pessoal das bibliotecas, voltada à especialização e à pesquisa. Se o colaborador não tiver um olhar de pesquisador social, será difícil convencê-lo da importância de captar as percepções dos usuários da biblioteca (LOPES, 2002).

São os colaboradores que auxiliam na implantação, continuidade e avaliação de todos os serviços e produtos disponibilizados pela biblioteca. Os funcionários da biblioteca estarão em contato direto com os públicos atendidos. As falhas, as necessidades de correções e acréscimos nos serviços prestados devem ser constantemente percebidas através do processo de escuta, conversas tanto com os colaboradores (usuários internos ou primeiros usuários) como das outras pessoas atendidas (usuários externos), os quais utilizam a biblioteca.

Pode-se dizer que a satisfação com os serviços e produtos disponibilizados pela unidade de informação é contagiante e necessita atingir, primeiramente, os usuários internos, pois são estes usuários que estarão em contato direto com o público externo. Este será "contagiado" com a satisfação comunicada dos colaboradores quanto à biblioteca.

É necessário reconhecer as diferenças socioculturais do grande público, não só dos letrados. Esse reconhecimento é imprescindível antes da elaboração de qualquer planejamento estratégico às unidades de informação. É preciso assimilar se a sociedade (letrados e não letrados) percebe a biblioteca como um tradicional espaço patrimonial, conceito de cultura a objetos inanimados, e também se a mesma estabelece relações sociais com a sociedade. O ideal é que essas unidades de informação sejam reconhecidas como objetos sociais de cultura em que as pessoas sintam-se parte dessas instituições (LOPES, 2002). 
Comunicar internamente é um conjunto de ações integradas que visam ouvir, informar, mobilizar, educar, manter coesão interna em torno de valores que necessitam ser compartilhados com todos. Um dos principais valores que se faz necessário ser compartilhado com os colaboradores é o de que a biblioteca é um organismo vivo, objeto de cultura social (todos devem fazer parte dela).

São essas ações conjuntas do processo de comunicação que conseguem lidar com a complexa gestão de pessoas, pois as motivam a expor suas opiniões, facilidades, dificuldades, talentos, criatividades, disponibilidades para contribuírem efetivamente com a elaboração e execução de qualquer planejamento estratégico bem como prepará-los para as constantes mudanças necessárias à biblioteca.

Após a implantação do conjunto de atividades de comunicação interna na unidade de informação, os funcionários saberão exatamente quais serão as vantagens da implantação de tal serviço, produto, e saberão transferir as importâncias para os usuários externos da biblioteca.

Nos últimos anos, as bibliotecas têm criado um sistema de comunicação externa cada vez mais complexo e com grande aperfeiçoamento do marketing externo e o uso da comunicação externa se potencializa ainda mais devido ao uso das redes sociais em linha. Mas a comunicação interna nem sempre sustenta ativamente a comunicação externa nos meios sociais. A estratégia de comunicação interna é imprescindível para aproveitar a sabedoria coletiva da organização e potencializar a capacidade de compartilhamento de conhecimentos entre os profissionais da biblioteca (CARRILLO POZAS, 2013).

Para a construção de um Plano de Comunicação Interna $(\mathrm{PCl})$, é necessário o planejamento inicial já visto o orçamento próprio e o pessoal responsável pelo $\mathrm{PCl}$. Para que a comunicação interna seja sempre inovadora, é viável aceitar todas as formas de informar (e-mail, bilhetes, críticas, boatos, escritos anônimos). Tanto o fluxo ascendente (chefias para subordinados) como o fluxo descendente (subordinados para chefias) de comunicação deve ser considerado. As avaliações e verificações de desempenho, efetividade do Plano devem ser constantes (PENA, 2007).

\section{PLANOS DE COMUNICAÇÃO EM BIBLIOTECAS}

Ao visar a um delineamento de um plano de comunicação interna em biblioteca, são tomados como base quatro exemplos de 
plano de comunicação interna em bibliotecas, os quais serão abordados logo a seguir.

\subsection{Análise do plano de comunicação interna da UNED}

O plano de Comunicação Interna de La Biblioteca da La Universidad Nacional de Educación a Distancia (UNED) da cidade de Madrid, Espanha (UNIVERSIDAD NACIONAL DE EDUCACIÓN A DISTANCIA, [2009]). Este é formado por oito (8) tópicos, uma bibliografia e anexos. Os tópicos são introdução; missão; visão; análise e diagnóstico da comunicação interna da Biblioteca da UNED; Análise das fraquezas, ameaças, fortalezas e oportunidades; linhas estratégicas do Plano de Comunicação Interna; objetivos estratégicos e objetivos operacionais; Evolução do plano de comunicação interna da biblioteca.

A introdução do plano de comunicação interna da Biblioteca de La UNED é composta por pontos os quais fundamentam a comunicação interna; a importância desse tipo de comunicação em bibliotecas; problematização e justificativa do plano de comunicação. O tópico missão possui uma objetivação cuja execução desta supriria as limitações de todos os fluxos de informação internos em todas as direções (descendente, ascendente e horizontal).

Esse tópico apresenta o que Torquato (1986) defende sobre a existência de redes formais e informais de comunicação. E que a rede informal é composta de manifestações espontâneas dos colaboradores, incluso as populares redes de boatos e os grupinhos.

Considerar todas as direções da comunicação interna, a saber: ascendentes (dos subordinados para as chefias); descendentes (das chefias para os subordinados); horizontal (redes de comunicação às quais abrangem todas as pessoas da instituição) supõe um respeito ao aspecto social dessa comunicação. Pois segundo Curvello (2012) a comunicação interna engloba a comunicação de âmbito social a qual inclui a difusão ideológica e simbólica da organização, ou mesmo a cultura organizacional. E por meio da percepção dessa cultura é possível visualizar as justificativas de sucessos e fracassos da instituição.

O terceiro tópico do plano (visão) descreve os objetivos específicos relacionados ao plano de comunicação.

A análise e diagnóstico da situação atual da comunicação interna são formados de resultados das impressões e opiniões do pessoal; análise da comunicação interna da biblioteca; fluxos de informação existentes; levantamento das ferramentas e recursos 
tecnológicos existentes; percepção da existência ou não de uma cultura institucional.

Fortalezas/oportunidades, fraquezas/ameaças estão listados em quatro (4) subtópicos. Há indicativos numéricos de relacionamentos entre fraquezas/ameaças e fortalezas/oportunidades: 0 nenhuma relação; 1 pouca relação; 2 alguma relação; 3 bastante relação e 4 muita relação. A somatória desses relacionamentos fez surgir, em ordem de prioridades, duas listagens: aspectos a corrigir; aspectos a potencializar.

O tópico linhas estratégicas do plano de comunicação corresponde às três etapas básicas do desenvolvimento desse plano. As linhas estratégicas são: a) Estabelecimento e melhora de um marco adequado para a comunicação interna da organização; b) Desenvolvimento e fortalecimento de uma cultura de comunicação interna na organização; c) evolução e melhoras contínuas. Cada quadro é formado por título (Linha estratégica) e quatro colunas (objetivos estratégicos; objetivos operacionais; responsáveis e prazos).

As linhas estratégicas do plano em questão remete ao que o autor Pena (2007) discorre sobre a importância da comunicação interna como instrumento indispensável à estratégia da administração, pois os processos de comunicação interna podem produzir participação efetiva dos colaboradores no processo decisório.

A seção "Evolução do plano de comunicação interna" também é um quadro de quatro colunas (objetivos estratégicos; objetivos operacionais; responsáveis e prazos) e o título do quadro é a linha estratégica c - evolução e melhoras contínuas.

\subsection{Análise do plano de comunicação interna da Biblioteca Universitária de Córdoba (BUC)}

O plano de comunicação interna da Biblioteca Universitária de Córdoba, Espanha (UNIVERSIDADE DE CÓRDOBA, 200?) é formado de um (1) tópico e sete (7) subtópicos. O tópico "comunicação interna" possui apenas um parágrafo e expressa a importância e justificativa do plano. Os subtópicos correspondem ao Plano de Comunicação Interna da BUC, os quais são: objetivos do plano; destinatários da informação (público-alvo); agentes encarregados de difundir a informação; tipologia das informações e do pessoal; atuações para melhorias; evolução do plano de comunicação e seguimento dos objetivos marcados.

O subtópico "Tipologias das informações" é formado por um quadro no qual estão discriminados os tipos de informação a serem 
veiculadas; o tipo de pessoal responsável por cada informação a ser comunicada e a periodicidade de cada veiculação de informação.

Nesse plano não há, aparentemente, uma preocupação com a captação da cultural organizacional, mas possui alguns dos tópicos os quais o autor Pena (2007) ressalta como essenciais a um plano de comunicação. Tais tópicos são: o que será comunicado; conteúdo das mensagens a serem comunicadas; pessoal responsável; avaliações constantes.

\subsection{Análise do plano de comunicación de la Biblioteca de la Universidad de Málaga}

O plano de comunicação da Biblioteca de La Universidad de Málaga no estado de Andaluzia, Espanha (UNIVERSIDADE DE MÁLAGA, 2005) é formado por três tópicos: Introdução; aspectos gerais; comunicação interna.

$\mathrm{Na}$ introdução, recorre-se ao processo de evolução de um plano de comunicação da biblioteca, o qual iniciou em 2003. É citado que o plano de comunicação se situa dentro do plano estratégico da biblioteca universitária. Há também um quadro com os nomes das pessoas que participaram da elaboração do plano. Esse tópico é concluído com a descrição dos objetivos e das justificativas à elaboração do plano.

A forma com que o histórico de evolução do processo de comunicação foi abordado demonstra o cuidado dos colaboradores da Biblioteca de Málaga ao fazer memória da cultura da organização. Para Shein (1986 apud Curvello, 2012), a cultura organizacional pode revelar-se em três níveis: nível dos artefatos visíveis; nível dos valores que direcionam o comportamento das pessoas (relatos, entrevistas) e o nível dos valores inconscientes (o que sentem, pensam, percebem). Ao relatarem o processo de evolução e ao citar o nome das pessoas que participaram da elaboração do plano, já demonstra tanto a valoração dos valores comportamentais (relato do processo durante determinado período) como dos valores inconscientes (valorização de sentimentos, pensamentos e percepções pessoais).

$\mathrm{Na}$ seção "aspectos gerais", há, inicialmente, a descrição de pontos de reflexão para preparação do plano de comunicação. Os subtópicos dessa secção são: diagnóstico da comunicação existente na biblioteca (comunicação interna e externa e os fluxos comunicativos existentes); definição dos objetivos gerais em tópicos; seleção de meios de comunicação (suportes escritos; suportes eletrônicos; suportes 
orais); nível de difusão (público-alvo); periodicidade de difusão; tipologia de informação a ser veiculada; evolução ou avaliação.

O tópico "comunicação interna" é formado por: introdução (conceito; objetivos e tarefa principal da comunicação interna); públicoalvo da comunicação interna; tipologia da informação a difundir (normativa; informativa); planificação das ações (ações básicas para continuidade do plano); esquema funcional (tipo de informação; conteúdo; periodicidade; nível de difusão; canal e responsáveis).

É evidente nesse plano de comunicação o cuidado dos colaboradores da biblioteca de Málaga com a escolha do canal de comunicação, ou mesmo, o que o autor Berlo (1972) chama de transmissor da mensagem, pois toda mensagem deve fazer sentido ao receptor.

\subsection{Análise do projeto de comunicação integrada para a biblioteca infanto-juvenil Monteiro Lobato}

O projeto de comunicação integrada para a biblioteca Municipal Monteiro Lobato (MONTEIRO; et. AL, 2013) faz parte de um projeto de extensão desenvolvido pelo Centro de Comunicação e Letras da Universidade Presbiteriana Mackenzie, em São Paulo. Trata-se de uma análise e estudo da comunicação da biblioteca, seguidos da elaboração de um produto e um serviço da informação à biblioteca.

O produto é uma cartilha, a qual auxilia os colaboradores da biblioteca quanto ao uso das ferramentas digitais e à alimentação de base de dados. O principal serviço gerado pelo projeto foi o de consultoria. Esse serviço foi focado na capacitação dos funcionários para se familiarizarem com as mudanças propostas no Plano de Comunicação Integrada. A primeira providência tomada para o estudo dessa instituição foi o mapeamento das seções e atividades que compõem a biblioteca por meio de conversas com os funcionários, direção, visitantes, parceiros, análise dos mercados e um estudo dos veículos de comunicação em circulação.

Realizar o mapeamento das seções de atividades da biblioteca por meio de conversas com funcionários, direção, visitantes é essencial ao processo de comunicação interna. Segundo Curvello (2012), esse processo é formado tanto de comunicação administrativa como também é constituído de comunicação social e interpessoal. Para Torquato (1986), a rede informal de comunicação (conversa, rede sociológica de grupinhos) permite o levantamento de manifestações espontâneas, importantíssimo em todo processo de comunicação. 
Capacitação dos funcionários, ou o serviço de consultoria para a implantação de mudanças no processo de comunicação da biblioteca é uma ação relativamente nova e indispensável. Segundo Curvello (2012), a comunicação interna, atualmente, serve não só para integrar os grupos ao interesse da organização, como era há um tempo, mas também para ouvir, informar, mobilizar, educar, capacitar, manter coesão interna por valores a serem compartilhados por todos da instituição.

Em acordo com o autor Berlo (1972), o processo de comunicação só ocorre quando o recebedor da mensagem consegue dar sentido e Ihe seja possível utilizá-la. Capacitar usuários é imprescindível para que todo o processo comunicativo tanto faça sentido aos usuários da instituição como lhes seja possível utilizaremse dessas mensagens recebidas em seu dia a dia.

\section{DELINEAMENTO DE PLANO DE COMUNICAÇÃO INTERNA À BIBLIOTECA DA CAJU}

A comunicação interna da Casa da Juventude é realizada por meio de redes formais e informais. A comunicação Interna formal é realizada via e-mail interno (Webmail), sendo que os envios de email, remetente e destinatário seguem a lógica do organograma vigente ou das reuniões do chamado Conselho Permanente, o qual é aberto a todos os colaboradores e ao Conselho de Jovens da Casa da Juventude. Nessas reuniões, existem curtos momentos nos quais letrados e não letrados (pessoal da limpeza, vigilância) podem expressar e fornecer feedbacks.

A comunicação interna informal é realizada pessoalmente ou via sistema sentimental. Na primeira forma, é possível fornecer feedback e compartilhar novos sentidos com o superior direto (relação interpessoal), conforme o organograma da CAJU. Na segunda, pode ocorrer a comunicação interna entre colaboradores de coordenações diferentes via sistema sentimental, ou seja, interações/comunicações informais em horários do café da manhã, durante alguns almoços oferecidos pela organização e nas comunicações informais ocorridas em corredores e dentro da biblioteca, esta apelidada de "Muro das Lamentações", pois recebe reclamações, sugestões à biblioteca e à administração da CAJU.

Ao elaborar um plano de comunicação interna à biblioteca da CAJU, a primeira providência seria realizar um levantamento formal (via webmail e aplicação de questionários) e informal (comunicação interpessoal), para descobrir, em primeira instância, se a biblioteca é 
vista pelos usuários externos como algo patrimonial (objetos inanimados distantes de pessoas) ou se ela é vista como um objeto social de cultura. Essa visão de biblioteca como objeto social é a ideal, pois o uso que os usuários fazem da biblioteca é diretamente relacionado com o tipo de visão que possuem sobre essa Unidade de Informação (LOPES, 2002). Caso o levantamento aponte a biblioteca Pe. Albano Trinks como uma instituição puramente patrimonial, será necessário proceder com a disseminação da informação de que a biblioteca é um objeto social de cultura e que todos fazem parte dela. Estima-se que o levantamento possa apontar vertentes de como os usuários podem passar a ver a biblioteca também como objeto social e parte de si mesmos.

Os canais utilizados para transmitir as mensagens da biblioteca seriam em vias formais o webmail (e-mail interno) e as reuniões do conselho permanente. Em vias informais, o canal para transmissão das mensagens da biblioteca seria uma cartilha educativa e um mural ilustrado. O motivo da utilização do mural ilustrativo é para que tanto os letrados como os nãos letrados sejam participantes do processo de comunicação interna da biblioteca. E o acesso às informações no webmail se restringe aos letrados. A cartilha educativa será distribuída a todos os colaboradores e cursistas atendidos pela Casa da Juventude. O conteúdo vinculado na cartilha educativa será transmitido também via webmail (e-mail interno) para apresentar a biblioteca como um bem sociocultural, para comunicar os serviços, produtos e normativas da biblioteca para todos os colaboradores e cursistas da CAJU.

É imprescindível a comunicação das novidades da biblioteca. Essa comunicação necessita de um meio mais reflexível e dinâmico. Por isso, o ideal é utilizar o site da CAJU e as redes sociais ligadas a ela para divulgar, mensalmente, as novidades da biblioteca como materiais novos recebidos; visitas ilustres; programações de oficinas de leitura e escrita e temáticas de varais literários. É necessário criar símbolos fixos para cada tipo de atividade, pois isso facilitará comunicar as novidades aos não letrados via mural ilustrado. $O$ site da CAJU e as redes sociais dessa organização conterão as informações existentes na cartilha educativa, mas a periodicidade de atualização dessas informações educativas será anual, devido às condições e às restrições orçamentárias.

As cartilhas educativas seriam produzidas, anualmente, e comunicadas pessoalmente, via webmail e em reuniões do conselho permanente com periodicidade trimestral. As novidades seriam produzidas e divulgadas mensalmente via assessoria de comunicação 
da Casa da Juventude. Essa assessoria estaria incumbida de realizar a editoração e impressão das cartilhas educativas. A elaboração das cartilhas, murais e noticiários de novidades estariam na responsabilidade dos responsáveis pela biblioteca e estagiários desta.

O planejamento e elaboração do orçamento anual incluiriam o conteúdo das cartilhas e murais e as despesas com a comunicação interna da biblioteca. A avaliação do processo de comunicação interna da biblioteca ocorrerá constantemente, via disposição de uma caixa de sugestões e reclamações. A análise e a comunicação do conteúdo seriam elaboradas mensalmente. O feedback obtido desses dados pode constar tanto no e-mail institucional quanto nas reuniões do Conselho Permanente. Ao perceber falhas no processo de comunicação interna, estas deverão ser corrigidas logo após cada reunião desse Conselho Permanente.

O Plano de comunicação Interna da biblioteca da CAJU constaria de uma introdução, com histórico detalhado da biblioteca; o diagnóstico da unidade de informação, o qual inclua a identificação da cultura organizacional da CAJU; objetivos; metas; Serviços, produtos e tipos de novidades a serem comunicadas; canais de comunicação a ser utilizados para cada informação; público-alvo e canal de comunicação ideal a cada pessoa ou grupo; periodicidade de cada informação; avaliação do processo comunicativo; implementação de mudanças conforme demanda ou falhas percebidas na comunicação; orçamento anual; conteúdo a ser abordado na cartilha educativa e mural ilustrativo; referências bibliográficas.

Acredita-se que um plano de comunicação à biblioteca da CAJU apontará a esta unidade de informação as possíveis estratégias de integração com seu público interno, bem como a motivação desses usuários a trabalhar e divulgar a biblioteca junto aos demais colaboradores internos (funcionários CAJU) e também aos usuários membros da comunidade externa (pesquisadores de juventudes; universitários; comunidades religiosas; comunidade em geral), servindo como planejamento estratégico à educação/capacitação dos mesmos colaboradores a reconhecer a biblioteca como objeto social e cultural e não como algo distante de suas realidades. Com a implantação do Processo de Comunicação Interna, estima-se que os serviços, produtos e atividades realizados por essa unidade de informação deixarão de ser isolados e distantes, fazendo parte da realidade cotidiana dos colaboradores externos e, por consequente, dos membros da comunidade externa. Acredita-se, portanto, que o plano de comunicação à Biblioteca Pe. Albano Trinks é um dos documentos principais a esta unidade de 
informação e, portanto, de caráter imprescindível no relacionamento e atuação dela junto a seus públicos interno e externo.

\section{CONCLUSÃO}

A revisão da literatura foi primordial para compreender o relacionamento entre a informação entendida como transmissão de dados presentes em algum suporte informacional ao longo de anos e a comunicação, compreendida como informação aos contemporâneos ou pessoas de uma mesma época. Antes de qualquer usuário externo, os usuários internos (ou colaboradores, como também são conhecidos) devem ser as primeiras pessoas a desfrutar dos serviços e produtos disponíveis na biblioteca.

A comunicação interna em bibliotecas é um processo que educa, capacita, motiva, incentiva a participação e auxilia na percepção da cultura organizacional e, consequentemente, podem ser levantadas as dificuldades, as facilidades, as resistências às mudanças, os talentos e a criatividade entre colaboradores de unidades de informação.

Ao analisar as teorias de comunicação e os quatro planos de comunicação em bibliotecas aqui apresentados, percebe-se que a elaboração do primeiro diagnóstico de uma biblioteca deve prever, antes de tudo, seu processo de comunicação interna.

São os colaboradores que auxiliam na implantação, continuidade e avaliação de todos os serviços e produtos disponibilizados pela biblioteca. Os funcionários da biblioteca estão em contato direto com os públicos atendidos. As falhas, as necessidades de correções e acréscimos nos serviços prestados devem ser constantemente percebidas através do processo de escuta e de conversas, tanto com os colaboradores (usuários internos ou primeiros usuários) como das outras pessoas atendidas (usuários externos), que utilizam a biblioteca.

A avaliação e posterior implantação de mudanças nos serviços e produtos só serão efetivas se houver o cuidado dos colaboradores em registrar e externar as reclamações, dificuldades e sugestões pessoais e as do público externo sobre a biblioteca. Esse cuidado em registrar e externar sugestões, reclamações é característico de pessoas com um olhar apurado de pesquisador. Surge, então, a necessidade de capacitação do quadro pessoal da biblioteca voltado à pesquisa social e, principalmente, voltado a processos de comunicação.

Por meio da comunicação interna, os profissionais da informação perceberão quais são as capacitações e canais de 
comunicação (formal ou informal) apropriados a cada colaborador.

O plano de comunicação à biblioteca da CAJU poderá trazer a esta unidade de informação vias e estratégias de integração com seu público interno (colaboradores), bem como a motivação deles em trabalhar e divulgar a biblioteca entre si mesmos e junto à comunidade externa.

Recebido em: 21 dez. 2017. Aceito em: 14 fev. 2019.

\section{REFERÊNCIAS}

BERLO, David K. Modelo do processo de comunicação. In: 0 processo de comunicação: introdução à teoria e prática. 4.ed. Rio de Janeiro: Editora Fundo de Cultura, 1972.

$\begin{array}{lcc}\text { CARRILLO POZAS, Ana. Comunicación interna en } & \text { bibliotecas. } \\ \text { Biblogtecários, } & 2013 . & \text { Disponível }\end{array}$

<http://www.biblogtecarios.es/anacarrillo/comunicacion-interna-en

bibliotecas/>. Acesso em: 10 mar. 2014.

CURVELLO, João José de Azevedo. Comunicação interna e cultura organizacional. 2. ed. Brasília: Casa das Musas, 2012.

DEBRAY, Regis. Transmitir: o segredo das forças e das ideias. Petrópolis: Vozes, 2000. $179 \mathrm{p}$.

HOUAISS, A., VILLAR, M. S., FRANCO, F. M. M. Dicionário Houaiss da Língua Portuguesa. Rio de Janeiro: Instituto Antônio Houaiss de Lexicografia, 2001.

LOPES, Luis Carlos. Comunicação e informação em arquivos, bibliotecas e museus. Conexão - Comunicação e cultura, USC, Caxias do Sul, v. 1, n. 2, p.105-112, 2002.

MACHADO, Irene. Ponto de vista semiótico. In: HOHFELDT, Antonio; MARTINO, Luiz. C.; FRANÇA, Vera Veiga (org.). Teorias da comunicação: conceitos, escolas e tendências. 4.ed. Petrópolis: Vozes, 2001. p. 295.

MARTINO, Luiz C. De qual comunicação estamos falando. In: HOHFELDT, Antonio; MARTINO, Luiz. C.; FRANÇA, Vera Veiga (org.). Teorias da comunicação: conceitos, escolas e tendências. 4.ed. Petrópolis: Vozes, 2001. p. 11-25.

MARTINS JÚNIOR, Joaquim. Como desenvolver um trabalho de conclusão de curso. In: Para escrever trabalhos de conclusão de curso: instruções para planejar, montar, desenvolver, concluir, redigir e apresentar trabalhos. 2.ed. Petrópolis, RJ: Vozes, 2008.

MIRANDA, Simão de. Preparação da pesquisa. In: Metodologia científica: os caminhos do saber. [s.l:s.n], 2011. Disponível em: 
< http://blog.fimes.edu.br/gildomar/files/2011/08/7299971-Pesquisa-eMetodo.pdf $>$. Acesso em: 01 out. 2013. p. 37-55.

MONTEIRO, Gabriel; et. al. Projeto de comunicação integrada para a biblioteca Infanto-juvenil Monteiro Lobato. In: Intercom - Sociedade Brasileira De Estudos Interdisciplinares da Comunicação, 2013. Anais eletrônicos... Disponível em:

<http://portalintercom.org.br/anais/sudeste2013/expocom/EX38-14771.pdf>. Acesso em: 28 maio 2014.

MULLER, Mary Stela; FORTES, Waldyr Gutierrez. Comunicação na biblioteca: uma questão interdisciplinar. Transinformação, v. 8, n. 2, p. 3344, maio/ago. 1996.1 Disponível em: $<$ http://www.brapci.ufpr.br/documento.php?dd0 $=0000000233 \& d d 1=b 5 f 7$ 7>. Acesso em: 1 out. 2013.

PENA, Antonio de Oliveira. A comunicação interna na filosofia da comunicação integrada das organizações. In: MARTINS, Moisés de Lemos; PINTO, Manuel (orgs.). Comunicação e cidadania: actas do $5^{\circ}$ Congresso da Associação Portuguesa de Ciências da Comunicação, 6-8 de Setembro 2007. Braga: Centro de Estudo e Comunicação e Sociedade (Universidade do Minho), 2008. Disponível em:<http://www.lasics.uminho.pt/ojs/index.php/ 5sopcom/article/ viewFile/18/19> Acesso em: 10 mar. 2014.

SEMINÁRIO NACIONAL DE BIBLIOTECAS UNIVERSITÁRIAS, 17., 2012, Gramado,RS. Anais... O papel da comunicação interna institucional na relação COMAUT - SBUFRGS. Gramados, RS: SNBU, 2012. Disponível em: <http://www.snbu2012.com.br/anais/pdf/4QDY.pdf>. Acesso em: 10 mar. 2014.

SILVA, Edna Lúcia da. A pesquisa e suas classificações. In:

Metodologia da pesquisa e elaboração de dissertação. $\overline{4 .}$ ed. Florianópolis: UFSC, 2005.

TORQUATO, Francisco Gaudêncio. Comunicação empresarial/comunicação institucional: conceitos, estratégias, sistemas, estrutura, planejamento e técnicas. São Paulo: Summus, 1986.

UNIVERSIDAD DE CÓRDOBA. BIBLIOTECA UNIVERSITARIA. Plan de comunicación de la Biblioteca Universitaria de Córdoba. Madrid: Universidade de Córdoba, 200?. Disponível em: <http://www.uco.es/servicios/ biblioteca/eyc/plandecomunicacion.pdf>. Acesso em: 10 mar. 2014.

UNIVERSIDAD DE MÁLAGA. BIBLIOTECA UNIVERSIDAD MÁLAGA. Plan de comunicación de la Biblioteca de la Universidad de Málaga. Málaga: Universidad de Málaga, $2005 . \quad$ Disponível em: <http://www.uma.es/publicadores/biblioteca/wwwuma/PlanHermes.pdf>. Acesso em: 10 mar. 2014.

UNIVERSIDAD NACIONAL DE EDUCACIÓN A DISTANCIA (UNED). BIBLIOTECA DE LA UNED. Plan de comunicación interna de la UNED. 
Madrid: UNED, 200?. Disponível em: < http://comunicacionbus.pbworks.com If/Plan_Cl_UNED.pdf >. Acesso em: 10 mar.2014. 